\title{
Living Tongue: The Proposal Speech in West Sulawesi, Indonesia
}

\author{
Nirwan* I Wayan Simpen Ida Bagus Putra Yadnya I Ketut Darma Laksana \\ Udayana University, Bali, Indonesia
}

\begin{abstract}
This article discusses about the marriage proposal speech through the linguistic anthropology perspective. Specifically, it elaborates the characteristics of the marriage proposal speech of Pakkado community in West Sulawesi especially on the aspects of parallelism and metaphor. The rationality of this study is to provide a better understanding of marriage proposal speech which is in line with the cultural aspect of the speakers. This research used participant observation method. The techniques used were recording and field note taking. The result of this study contributes in two factors: ethnography and academic. Ethnographically, the marriage proposal speeches which are dialectically produced by the community are very heterogeneous. Theoretically, the speech is not only referential, but also indexically non-referential. The result showed that the proposal speech displayed varieties of metaphor and parallelism,
\end{abstract}

Keywords: Pakkado proposal speech, metaphor, parallelism

DOI: $10.7176 /$ RHSS/11-6-04

Publication date:March $31^{\text {st }} 2021$

\section{Introduction}

Language as the media used by community can bring up an interesting language phenomenon as a cultural practice (Duranti: 1997). This practice is manifested in language activities through conversation. The conversation itself is defined as a cultural activity that plays an important role in generating and maintaining individual and community cultural habits, such as identity, ideas, subjectivity, attitude and values (Keating dan Egbert: 2004). The conversations come up in various social situations, both in daily and ritual activities, for example, the conversation between parents and children in daily activities, the dialogue between men and women who are flirting each other, the communication between students and their lecturer, and people discussing or argumenting. The conversation is also denoted through the dialogue between women's and men's families in the marriage activities which is the focus of this research.

Language is the media among God's creatures, both between human and human, human to nature and to God. It indicates that the language cannot be separated from human's life. Therefore, it is not appropriate discussing the language by separating it from the context of humans' interaction or social life. Language studies that only focus on the internal elements of structural aspects are the examples of denial of the nature of language. Naturally, the language is relational. Therefore, language studies must follow its natural character.

This research follows the nature of language, in which it observes the language practices that are always in correlation with the culture of the speakers and also evaluates the social relationship that are built through these practices. In the context of marriage, the object of this research is the actors who are involved in performing the dialogical and contested actions through the use of language.

In Pakkado' culture, marriage proposal is one of phases that everyone must go through if they want to build a marriage life. In this phase, there is an interesting language phenomenon to analyze. This is the basis for the researcher choosing the social situation of the marriage proposal practice as his research topic. For example, speakers who are believed appropriate to be the family's representative, both from the bride's and the groom's family, often use poetic utterances, indexicality and sometimes quoting ancestral expressions. In addition, there is also contestation in the producing the utterances. The more proficient the actor, the more metaphoric the language used. If the negotiation is carried out properly, it can affect the quantity of dowry demanded by woman's family. To better understand this interesting phenomenon, it requires a depth ethnographic research.

This research certainly does not only focus on structural aspect of the utterances in marriage proposal, like those which are previously conducted by the structuralists. They are only interested in elaborating language or competence aspect of the language. However, to maintain the micro linguistic study, the researcher also investigated the internal aspect of the speech. Meanwhile, to keep it on the right track as an interdisciplinary research, then the cultural context becomes the focus of the analysis. The proposal speech will always be related to cultural context of the speaking community. As a result, the structural and pragmatic aspects of the language can be maintained equally.

The researcher investigated comprehensively and elaboratively about marriage proposal in which the main focus was headed to the aspects of utterances and the relevant cultural contexts. The rationality of this research is to provide a better understanding of the characteristics of the proposal speeches especially those related to metaphor and parallelism. 


\section{Ethnographic Research Context}

This research was conducted within the scope area of Mamuju district, precisely in Tapalang sub-district. Since the area is too large, the researcher chose several villages which are categorized as Pakkado community as the research object. There are some arguments regarding the selection of Pakkado sub areas and community as the research object. First, Pakkado community, in the history of cultural diffusion was mountain people or in the local language identified as to pa'anete 'people from mountains coming down to coastal areas and categorized as to pa'bering bonde' 'people who lived near the coast. There was an assimilation of cultural language practices from mountain and coast. This assimilation practice is the reason of the selection of research location. Second, there has not been any research which specifically and comprehensively elaborated the characteristics of marriage proposal utterances in Pakkado community. Third, the researcher considered to undergo the in-depth analysis related to the proposal of marriage because he himself is the native speaker of Pakkado.

In exploring the phenomenon of language use in the context of marriage proposal; the features of speech, the forms of participation, the emergence of language ideology and the ways of language indexes its speakers' culture, there are several factors should be discussed such as religion, geographical and economic condition because these factors give direct effect on the implementation of marriage proposal events.

\subsection{Pakkado' Society}

Pakkado is the identity for communities who refer the pronoun 'I' as 'kado'. It consists of two words, $p a$ ' as the prefix refers to people. This word will have meaning if it is followed by the word like kado' which means 'I'. Commonly, non pakkado people call them to pakkado which means 'people who speak I'.

This naming is different from the naming of other communities, such as pannei', pattae', and some other group societies. The Pakkado speakers outspread in various regions in West Sulawesi. In the history of language spread in West Sulawesi, Pakkado is commonly known as one of dialects in Pitu Ulunna Salu language, even though in fact people name it bahasa or basa (local language).

The community who identified themselves as Pakkado, which was the location of this research, is located in Mamuju district. To identify the people who use Pakkado dialect, it only needs to notice their first singular pronoun, namely kado which means 'I'.

\section{Theoretical Foundation}

This study used several analytical tools developed in linguistic anthropoly studeis, namely the concepts of parallelism and metaphor.

\subsection{Parallelism}

This concept was found in Jakobson's writing. The term of poetic was proposed by Roman Jakobson through six language functions. The poetic function works for the benefit of the message delivered 'the message for its won sake' (Jakobson [1960:353]). Message construction is based on the interaction between selection and combination levels or in Saussure's term (1966), it is between syntagmatic and paradigmatic levels. Jakobson explains it in detail;

Poetic function project the principle of equivalence from the axis of selection to the axisi of combination, which lead to parallelism like identification and differentiation or repetition with variation and one form of repetition is parallelism (Jakobson: 1960).

Parallelism in this research is used to observe to what extent the poetic aspect of proposal utterances used in the conversation. The antrhopolinguist who plays important role in analyzing parallelism, especially in the eastern part of Indonesia is Fox. Most of his studies discuss the ritual speech. The result of his studies is that the ritual speech in eastern Indonesia is characterized by a high use of parallelism. Therefore, this concept is tested through marriage proposal speech.

Jakobson's poetic theory through the aspect of parallelism is used to investigate the entire state of the text. This theory answers all research questions, whether the marriage proposal speeches are characterized by the use of parallelism or they only the ordinary language spoken by the speakers in everyday conversation. Generally, marriage proposal speeches are very paralellistic, however they are highly determined by the role of social actors. This aspect is greatly influenced by the speakers' knowledge.

\subsection{Metaphor}

Language is organized by a metaphorical system of thinking which is arranged into a hierarchical structure. Metaphors are tools of peotic imagery and fascinated rhetoric which are different from the ordinary language. Etymologically the term metaphor derives from the Greek word, metaphor, which consists of two words; meta which means half and phora which means reference.

Aristoteles in Sugiharto, 2006:13 describes three characteristics of metaphor. First, the reality of metaphor is something that is imposed on a noun or associated with an object. Second, metaphor is limited in the context 
of movement (epiphora), namely the transfer or movement of one object to another and applied for all forms of term transpositions or with other descriptions. Metaphor contains a different meaning from the original one. Third, metaphor is a transposition of a 'foreign' (allotrios) name. It is a name that actually belongs to another object. It means that the object used as a comparison is only an entity which represents another meaning or the intention of the speaker.

Some linguists describe the definition of the term metaphor. For example, Saragih (2013:201) says that metaphor is a meaning from two sides, namely one meaning or concept is encoded from two sides or one meaning is interpreted from two sides. Based on that comparison, there is the identicality or similarity between one symbol and another. Riemer (2010:246) states that metaphor serves to emphasize the similarities between two entities. Furthermore, Geeraerts (2010:204) explains that metaphor is the mechanism of seeing one thing in another. Lakoff dan Johnson (1980:5) in Metaphor We Live By argues that the essence of metaphor is to understand something in another way. Based on Ricoeur (2005:86), metaphor is the result of the suspense of two terms in a metaphorical expression.

The comparison of two entities or symbols in metaphor aims to find the meaning of a symbol in one object that is in accordance with the unique characteristics of the reference symbol. Therefore, comparing one symbol to another requires the accuracy so that the meaning built is a good and appropriate one. According to Foley (1997), metaphor is related to the arrangement and selection of features to understand a target/symbol. In another view, Fill \& Mühlhäusler (2011) convey that metaphor is likened as a spotlight which is able to illmuniating the dark sides of one sign. It means that metaphors look for the bright spot of a sign by comparing it to another sign. The result of the comparison then reveals the hidden meaning of a sign.

It needs the interpretation in explaining the meaning of metaphorical sentences because those sentences do not refer to the physical meanings or sentences that construct them. However, the intended meaning lies in the mind or in internal part of a word or sentence. This is in line with the view of Ricoeur (2005:87) who says that metaphors do not exist in themselves, but live up through the interpretation. This interpretation then produces something new about the reality.

From all definitions of metaphor above, it can be concluded that metaphor is an effort of combining two entities to produce a new meaning that is different from the original one. This metaphoric concept is used to view and interpret the speech of marriage proposal activity. There is a view says that humans live in a metaphorical world. Therefore this view becomes a guiding idea for the researcher to observe that the marriage proposal texts are filled with metaphorical expressions. Living in a metaphorical world means all aspects of life including human language activities show metaphorical aspects.

\section{Data dan Discussion}

The research has successful in collecting data on proposal 'speech. The text characterized the using of metaphor and parallelism. The following text obtained from the informants. The speakers of the text below consist of three men that considered as a representative of two families: the big family of man and woman. For the shake of clearness in identifying and understanding the structure of the text, the writer named every speakers with the symbols S1 for first speaker comes from the family of man, S2 for second speaker categorized as family of woman and S3 for third speaker as part of S1.

S1: $\quad$ Na niende inde bojang anna malakka dai' talaniende anna pandeng diaya

There is a beautiful woman on this tall house

S2: $\quad$ Endeo mai diboyang digalaqgar tirisi, andiang roko podo loa mapia.

Come to the broken floor house, there is not cigarette but good talk only

Teemmi tandee to makaka

Like this tomakka (commonly used for high social class people)

nasanga basa basa mangaraqta mangngoa

According to the words said that

moa iya lessuq mi indee tula'ku dingena

I have told to you

Endeo mai diboyang digalaqgar tirisi

Come to the poor man house

Tapi tatta indee namettule indee.

I have to ask this

Mangoa ya' Aka le 'ba indee Akkatamu anna manediammu koa kuita lambi.

I said, what is the main purpose of your coming?

Silambi lolo ria tau biasanna siduduatta. Maiqdi iqdi koaq kuita lambiq.

We usually meet but now you come with many people

Angga'na diakkusaqding indeqe maqbattuang indee kalambiammu indee tomakaka.

I believe that you have purpose 
S1: Ya iyo, diassi'da tetoda indee ya

Yes, yes. There is purpose

U'de diang appo mala ningoa diassisiqda toi indee tomakaa

There is not but I can say we have purpose

ya Yaq indee Kuakkattai indee mai dinoa

My purpose for coming today is

Namettulea indee tomakaka, keiissi raka inde sapota lo'bang daka?

To ask, is this house empty?

S2: $\quad$ O iyo, Anu mapia iting tomakaka.

Ow yes. That's good purpose

Yaq Alhamdulillah

Yes, price be to Allah

sementara inde dinoa moa naiya riko iting mupenandai yaq, namuakkattai

Nowadays, If your purposes is to look for the house

toko nipakadoro karo'bangi tandee sapo.

Honestly, the house is empty

karo 'bang sapo jari indoo aka karoqbang sapo ya terserattea

This house is empty and now it depends on you

umba kita akkttata selanjutna akaq muringing indee tula

what is your plan, because you have heard this talking

S1: Yaq kuissammi taiting, ya diang aka indee.

I have understood, there is something

nasioa indee mai ana'mu nangoa tama rako di puaq di tomakaka,

I am asked by your child to meet the puaq (father of male)

ee mepasappe ari disali sambessaqna di kalakkaq sassigiqna.

S2: $\quad$ Yaq toko makasiqda raka iya iting tomakaka.

That's really good

aka nasanga basa basa iyang iting na niakkttai

according to common words that that's our purpose

akaq nasanga pole basa tobaraq baraqta.

According to old people

Moaq sitinajanna tea namappoliq tau lolo bojoq

We must hold the top of the pumpkin's trunk

aka lambanattea le'ba indee

because it goes slowly

ya nasanga basa yaq aqderang tea niissang mennarang indee

according to the common words we don't know who is this?

ya wattunna dinoa iting moaq toko anu

This is the time

Alhamdulillah akaq mesa akktta tau iting.

Prise to God because we are one purposes

S2: $\quad$ Iyaq iarattandee, kada iyarattaiting indee tomakaka

Yes, that the word

nitokei lolo pasanna tomatuatta indee mai mangoa mappoliq tau loloqna bojo

According to old people we must hold the top of the pumpkin's trunk

sehingga iya mutuq kepettuaing indee rapang maiq mettu mettuleq di kitaq

So, I come for asking.

S1: $\quad$ Alhamdulillah

Prise be to Allah

Iyaq toko namepatudung tetau jolo indee Tomakaka

We will teach this first Tomakaka (refers to social high class person)

si duambengi tattangngaiaq. insha allah ee

We will waiting for two nights. God willing

aka indee ia dinoa nasanga,

Because of this, today is said

yaq tettoboia adaq biasa annaq kemudian indee tea moade nipateeng,

That's ours culture, if it denies

jangan sampai massalasohong tau dingena menjari masapopissang 
it can effect on our relationship

S2: $\quad$ Yaq Alhamdulillah.

Prise be to Allah (God)

S3: $\quad$ Cuccurukuq, cuccurukuq, cuccurukuq

This sound refers to the sounds of hen

S1: $\quad$ Ganna mi tea tallung bengi tomakaka akaq mepponiang ia maneq,

[The hen' sound means the time has arrived]

Yaq toko napoeloq toia indoo anaqmu.

[Your son wants that]

Nipattemmi ningoa manequ

[Let's say my hen]

Alhamdulillah toko mesa hanya ria supu meloq indee kupettuleang.

[Prise to Allah, I have one question to ask]

Aka namubabe indee, mappakande tetau indee maneq.

What will you do?, we will be giving food to the chicken.

Aka iko siarang ia, mappakande tetau maneq, yaq ude tea namusala iko riko

Name pattulaqi mai

Because, it depends on you. We give food to the chicken. I should not ask you because you know this well.

A1: $\quad$ Yaq indee dinoa tomakaka aka anggaqna yaq matua ai tandee bulang indee

[Today, the time has come]

yaq sombo sombona bulang indee.

[The rise of moon]

Muda mudahang indee yaq mala indee

[May this intention can be done]

mangola maiq Mappapaqrupa mengaka akttaku

[I come here for making clear of my intention]

akaq niissammi indee mangoa yaq loqbang di indee sapo

[Because we know the house is empty]

A1: $\quad$ Yaq iyo natemmi tandee.

[Yes, there it is]

A2: Jari Indoqo iya, sombopi bulang,

[So, we wait for rise of moon ]

nasanga basa silambiq borattau, nasiteppo rang tau

[According to usual talk, we will meet again. We promise to meet again]

\subsection{Metaphor}

The first characteristic that is found and become the focus of analysis is the metaphorical aspect. This text is marked by the use several ecological metaphors, more precisely the metaphors of flora and fauna because it takes several objects from forests and animals.

Metaphor is a tool of poetic imagery and rethoric that lives in society and is categorized as extraordinary language which is different from the ordinary or everyday language (Lakoff and Jhonson). As a means of imagination and persuasiveness, it means that metaphor is mind games. The essence of metaphor is understanding and experiencing one phenomenon in relation to another. Metaphor cannot be separated from human life because humans live in metaphor (Lakoff dan Jhonson). One of the places where metaphors are executed is in the event of marriage proposal.

Pakkado people through their oral tradition have resources of ecological metaphors. Therefore, in the result it was found that there are many ecological metaphors or the metaphors coming from flora and fauna. It indicates that there has always been a trace of the ability to think and process words; the ability to think in relation, connecting one object to another.

There are a number of metaphorical expressions found in the engagement speech of the two actors involved. Some of these metaphors are purely the creativity of each actor and some others are taken from elders' words as a legacy of past artifacts. Below are the examples of those data.

\section{A1. Na niende inde boyang anna malakka dai' talaniende anna pandeng diaya}

[There is a beautiful woman on this tall house]

Data [A1] above is the sentence of the male family to the female side. It is called local rhymes. The actions of male family as the initiator to start the conversation shows that in West Sulawesi society, especially the Pakkado community. The metaphorical expression is found in the word 'woman'. The metaphor word used to replace 'woman' in that sentence is pandeng 'pineapple'. 
In its entirety, the sentence above is poetic and rhetorical. It becomes peotic not only because of the use of metaphor but also because the sentence is able to display binary opposition, lower and upper positions, in which the man who is in the lower position will go up to the house to come to the woman who is in the upper position. Furthermore, it becomes rhetorical because the sentence invites people to meet the woman in the upper position even though the house's stairs are high. It does not matter with the high house's stairs as long as they can meet the woman.

Another point to notice is the use of the word $\mathrm{Na}$ niendeq 'go up' instead of Na tama 'come in'. The root of $\mathrm{Na}$ niendeq is endeq 'ladder'. This word describes the activity of someone climbing the house stairs. In addition, it also indexes the architectural design of the local people's houses, namely the stilt houses. As a result, the sentence above does not use tama 'come in' which refers to the way of entering modern houses that do not have stairs for coming in. Traditional houses of Mandar community, especially Pakkado are stilt houses or so called sapo mekke'ede 'standing houses'. To enter the house, people need 'erang' or stairs. With this reason, it is more appropriate to use the word 'go up'. Currently, these traditional houses are slowly lessening because they are replaced by the modern ones.

\section{A2. Ende'o mai diboyang digalaqgar tirisi, andiang roko podo loa mapia}

[Come to the house with broken floor, there is not cigarette but only good talk]

The sentence [A2] is the answer of sentence [A1] which was said by woman's family or designated as the representation. The sentence is in form of local poem that shows a metaphorical form through the use of the prepositions digalaqgar tirisi 'a house with a shifted floor support and andiang rokoq 'no smoking'. The floor support will usually be shifted if someone is sitting or walking on the floor. Cigarettes are the representation of food that are usually provided in a wedding ceremony. To better understand the sentence above, the translation of each word is given as follows.

Digalaqgar tirisi [di (prep) + galaqgar (floor's holder) + tirisi (shake)]

Andiang rokoq [andiang (there is not) + rokoq (cigarette)]

In Pakkado community, Gala'gar tirisi is associated with a very simple house and its design is a house on stilts so the metaphorical sentence Diboyang digalaqgar tirisi means the effort of the woman's family to show their social and economic status which is in the lower or underprivileged level. This action indicates the politeness of Pakkado community culture which is a form of denial of stability and arrogance.

Andiang Rokoq 'no smoking' is the prohibition sentence that is deliberately pronounced to inform that the food and the like are not the main subject of the meeting because the most important one is the good quality of the conversation. In this part, it is obvious that a good conversation is the one discussing the eagerness of a man to propose a woman.

\section{[A1]. Mepasappe ari disali sambessaqna dikalakkaq sassigiqna}

[Perhaps, they put us on the piece of floor and a half of floor]

Data [A1] shows a metaphor sentence taken from two parts of the stilt house, namely disali sambessaqna 'on a half of the floor' and dik alakkaq sassigiqna 'a piece of floor support'. This sentence starts with the word mepasappe 'to put' and is usually used for things that are placed on a high position so they do not touch the ground.

Sentence A1 is very metaphoric. The actor wants to describe his hope metaphorically to be accepted by the woman's family, even though they are placed on a half of the floor and a piece of pole. From this sentence, it denotes that there is a strong willingness from male's family to bond the family relationship through marriage. The structures of Pakkado community's houses consist of poles, floor supports, floors, and roofs. The preceding sentence borrows part of the floor and supports. The floor is made of bamboo which is split into small pieces and the supports are made of wood.

\section{[A2]. Moa sitinajanna tea namappoliq tau lolo’ bojo'}

[Rolling the tip of a pumpkin']

The expression in A2 is a conditional sentence which is seen in the use of the word moa 'if'. The metaphorical expression appears through the use of phrase taken from the plant namappoliq tau lolo' bojo 'rolling the tip of a pumpkin'. Pumpkin is a type of vegetable that is generally consumed by people and its leaves vine on the ground.

The sentence above conveys the meaning of an effort to unite to families in a bond of marriage, such as the joining of two ends of pumpkin trees when they are brought together. This expression is popular in the context of a meeting discussing a marriage and has become inheritance expression from the elders. In this sentence, it can also be found another metaphorical expression by taking the name of another plant.

\section{[A2]. Ganna mi tea tallung bengi tomakaka akaq mepponing ia maneq}

[it has been enough for three nights]

The sentence A2 metaphorically refers to time in which it is represented by the use of the word animal and time, namely mane 'cock' and bengi 'night', as in the expression ganna'mi tea tallu bengi 'it has been enough for three nights', and mepponiang ia mane 'the cock crows'. The interesting part is the presence of non-verbal 
sign. This sign is shown by the representative from male's family by playing the role of a rooster that crows three times. The reconstruction of the three-time crows is symbolically interpreted as a marker of time. This phenomenon shows a riveting non-verbal performance. The three times crows that are sounded in seconds have equal value as those did in three days and this action can be accepted by the woman's family.

To understand this performance, it is necessary to focus on the pretext that preceded it, namely about the agreement. The woman's family needs three days to decide whether the intention of the man's family accepted or not. The non-verbal performance above is the response of the family to notify that the three days of the interlude time have come.

[A2]. Aka namubabe indee, mappakande tetau indee mane'?

[What will you do because we want to give food to chicken?]

The use of metaphor also appears in sentence A2 above, namely the word mane 'chicken'. In the context of conversation, proposing the chicken is the metaphor for women. In Pakkado community culture, when a man and a woman get engaged, during the engagement time the woman is endured by the man by giving her food and clothes. It means that the woman cannot accept other men's proposal because she has already been proposed.

The engagement can stop or break up or in other word the man and the woman do not reach the marriage stage for some reasons. For example, the male's family is unable to fulfil the request of the female's family. Pakkado community use the engagement as the time to collect all requirements of the woman, such as dowry and other items needed. Pakkado people are different from Toraja community. In Toraja, the most luxurious cultural activity is the death. In Mandar community, especially pakkado, wedding party is the most festive cultural ceremony.

[A2]. Moaq mennasa indee dio diangmi massalokko

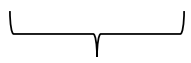

\section{[A2]. Diang mi mattujuq tomakaka temmi tandee}

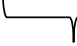

Sentence A2 deploys the use of the metaphor words, namely massalokko 'to enclose' and mattuju 'to tie'. These metaphors play on a lexical level. Although these two words are different in terms of form and meaning, their functions are the same. These two verbs are used to keep the chicken from running away and wandering around. Those verbs are salokko and petuju. Salokko means locking up by putting the chicken in the cave. Petuju 'rope' is used to tie the chicken's feet. The point is the chicken is in a safe place with its owner.

Initially, these two words are used to keep the animals, but then the actor reconsidered it to the context of marriage proposal by no longer referring it to chicken but to humans, namely women. The meaning of those words remains the same without undergoing changes, but the object changes from animal to human. This metaphor indicates that like a chicken, the woman is safe because she has already been in the owner's hand. In engagement context, the woman has already been proposed, so it is impossible to accept another man's proposal. There are lots of metaphors describing women in the context of marriage. The researcher needs ethnographic research to find these metaphors.

Based on the result of the analysis and interpretation of proposal texts above, it shows that there are lots of metaphors. It indicates that Pakkado community is accustomed to metaphorical and relational way of thinking; a holistic thinking model where all natural facilities are used in conveying ideas through conversational activities.

\subsection{Parallelism}

The second characteristic of the text found as the cultural property through the language activities is the use of parallelism. Parallelism is the result of the actor's individual creativity that is spoken spontaneously in responding to the opponents' sentences.

Parallelism is the aspect of speech characterized by repetition, synonym, antonym, and opposition. The term poetic is proposed by Jakobson in six language functions. One of them is the poetic function. The poetic function projects the equivalence from the selection axis to the combination axis as parallelisms which are seen in identification, differentiation, and repetition. Parallelism is found in many ritual speeches. Ritual speeches commonly have parallelism characteristic in which one word or sentence is repeated several times (Fox: 1988). One of the functions of parallelism is to emphasize the importance of the message conveyed.

Apart from the ability of using ecological metaphors, the Pakkado community, through the marriage proposal speech is also able to show expertise in composing parallelism. One word is repeated twice. The common parallelisms found are in words; one different word is repeated but it has the same meaning. The texts below are the example of parallelism. 
Metaphor
Parallelism $\left\{\begin{array}{l}\text { Moa mennassa inde'e dio diangmi massalokkoq } \\ \text { Diang mi mattujuq tomakaka temmi tandee }\end{array}\right.$

The sentences above reveal metaphorical parallelism by the use of the word massalokko 'to enclose' and mattuju 'to tie'. In the history of their use, these words are generally used for animals, especially chickens. In the context of marriage proposal they are referring to women. This is one of the ways of using metaphor performed by the actors. The word massalokko refers to two elements, related to activity and the artifacts. The activity meant is to keep the chicken inside by using the artifact or a traditional tool called salokko. This cultural object is made of bamboo. In other word, massalokko means to hold the chickens in so that they do not escape and roam. While the word mattuju means 'to tie'.

Parallel $\left\{\begin{array}{l}\text { Ya iyo, diassi'da tetoda indee ya } \\ \text { [Yes, there really is] (A1) } \\ \text { Ude diang appo mala ningoa diassisiqda toi indee tomakaka (A1) } \\ \text { There is not, but there really is. }\end{array}\right.$

Parallelism expression can be seen in the last sentence diassi'da tetoda indee 'there really is'. The two sentences above were delivered by the same actor, namely he from the male's side. One sentence which is repeated twice is an example of repetition. It functions as an answer and as an emphasis on the sentence of the Actor 2 (A2) who guess the intention of the arrival of male's family (A1). Nitokei lolo pasanna tomatuatta indee mai mangoa mappoliq tau loloqna

Parallelism

$$
\text { bojo'. (A2) }
$$

\section{Akaq nasanga pole basa tobaraq baraqta, moaq sitinajanna tea namappoliq} tau loloqna bojoq (A2)

There is also parallelism in the sentences above uttered by the two actors (A1 and A2). This is unique because the repetition sentence is the metaphorical sentence. Therefore, in this part, it is called metaphorical parallelism. Repeating the metaphorical word lolo' bojo 'end of pumpkin tree' depicts the effort to unite the kinship through the marriage bond.

Parallelism is the rethorical tool functioning to emphasize the message conveyed. In addition, the use of this form shows the actor's ability to select different words that have the same meaning. Therefore, it clearly signifies several forms of parallelism playing words and sentences. The level of the use of parallelism depends on the ability of the actors. It is the result of their creativity.

\section{Conclusion}

Marriage proposal' speech indicate diverse and strong characteristics of the texts. These characteristics become the resource of texts resulting from cultural events named marriage and intellectual property of Pakkado community. Some of the characteristics of the text are metaphor and parallelism. First is the use of metaphor. The form of metaphor is quite eclectic because it borrows animal names and parts of house. Hence, this kind of metaphor is called ecological metaphor. The second characteristic is the use of parallelism. This form presences in a number of lexicons. The lexicons have the same meaning but pronounced with different lexemes. This is the result of actor's creativity.

\section{References}

Duranti, Alessandro, 1997. Linguistic Anthropology.Cambridge University Press.

Fill, Alwin \& Feter Mühlhäusler. 2001. The Ecolinguistik Reader: Language, Ecology, and Environment. London \& New York: Continuum.

Fox, James, J. (1988). To Speak in pairs essays on the ritual language of Eastern Indonesia. Cambridge University Press.

Geeraerts, Dirk. 2010. Theories of Lexical Semantics. University of Oxford: Oxford University Press.

Jakobson, Roman, 1960. Closing statement: Linguistics and poetics. In Style in language. T. Sebeok, ed. Cambridge, MA: MIT Press.

Keating, E. \& Egbert, M, 2004. A Companion to Linguistic Anthropology. Editor Alessandro Duranti, Blackwell 
Publishing.

Sugiharto, B, 1996. Postmodernisme: Tantangan Bagi Filsafat. Kanisius. Yogyakarta

Saussure, Ferdinand de, 1996, Course in General Linguistic. New York: The Philosophical Library inc.

Saragih, Amrin. 2013. Semiotik Bahasa: Tanda, Penanda dan Petanda dalam Bahasa. Medan: Sekolah Tinggi Pascasarjana Universitas Negeri Medan.

Ricoeur, Paul. 2005. Theory of Interpretation: Discourse and the Surplus of Meaning. (Diterjemahkan oleh Mansur Hery dengan judul Filsafat Wacana: Membedah Makna dalam Anatomi Bahasa). Yogyakarta: IRciSoD.

Riemer, Nick. 2010. Introducing Semantics. New York: Cambridge University Press. 